\title{
Actinobacillus actinomycetemcomitans causing a mediastinal abscess
}

\author{
SM GARLAND, MG PRICHARD \\ From the Departments of Microbiology and Thoracic Medicine, Royal Melbourne Hospital, Victoria, \\ Australia
}

We report what may be the first documented case of an anterior mediastinal abscess due to infection by Actinobacillus actinomycetemcomitans. This small, fastidious Gram-negative coccobacillus is a normal component of the oral flora of healthy individuals, ${ }^{1}$ but rarely a human pathogen. It was first described in 1912 by $\mathrm{Klinger}^{2}$ in association with actinomycosis and has since been identified as the sole aetiological agent in at least 52 cases of bacterial endocarditis in North America and Europe and in isolated cases of brain abscess, meningitis, urinary tract infection, pneumonia, thyroid abscess, and soft tissue and wound infections. ${ }^{3-6}$

\section{Case report}

A 50-year-old man presented with a 10-week history of pleuritic interscapular pain and a dull pain in the left upper arm radiating to the praecordium. Physical examination and a chest radiograph showed nothing abnormal initially or at review two and five weeks later. After nine weeks a painless, non-pulsatile, erythematous mass $6 \times 4 \mathrm{~cm}$ developed on the anterior chest wall around the second and third costal cartilages while he was pulling fence posts from the ground. The patient also noted night sweats, palpitations, and tiredness but no weight loss. On admission to hospital four days later he was afebrile and, apart from the chest wall mass, there were no abnormal physical findings. The chest radiographs (figure) showed a large anterosuperior mediastinal mass. Dental and paranasal sinus radiographs were not obtained. Other findings were: Hb $12.9 \mathrm{~g} / \mathrm{dl}$, WBC $19.7 \times 10^{\%} / 1$ (80\% polymorphs), ESR $82 \mathrm{~mm}$ in one hour. Ultrasonography indicated a cystic mass superior and anterior to the aortic root and a gallium scan showed increased uptake limited to this area. Neither fibreoptic bronchoscopy nor mediastinoscopy showed any abnormality. Surgical exploration of the chest wall mass showed a subpectoral and anterior mediastinal abscess, which was drained. Biopsy specimens of the abscess wall showed non-specific subacute inflammatory infiltration. There was no evidence of fungal, actinomycotic, or tuberculous infection. Small Gram-negative coccobacilli in pure culture were isolated from pus collected from the abscess at surgery. The organism was identified as $A$ actinomycetemcomitans on the criteria of Cowan and

Address for reprint requests: Dr MG Prichard, Department of Pulmonary Physiology, Sir Charles Gairdner Hospital, Nedlands, Western Australia 6009.

Accepted 15 November 1982
Steel, ${ }^{7}$ and was sensitive to ampicillin, erythromycin, cotrimoxazole, and tetracycline and resistant to penicillin and lincomycin. The patient's plasma immunoglobulins and cutaneous delayed responses to common antigens injected intradermally were normal. Treatment was commenced with oral amoxycillin, $1 \mathrm{~g}$ six hourly, and probenecid, and was continued for four months, during which time the abscess resolved clinically and radiographically. One year later, at the time of writing, the patient remained well and his chest radiograph showed only mild residual mediastinal widening.

\section{Discussion}

This patient made an uneventful recovery from subacute suppurative mediastinitis, and we remain uncertain of the portal of entry of this organism or why it became pathogenic. He showed no evidence of dental disease, oesophageal perforation, granulomatous disease, bronchial obstruction or infection, malignancy, parenchymal lung disease, or immune deficiency. The most likely route of infection was through the anterior chest wall, perhaps because of blunt trauma to the sternum or ribs caused by lifting fence posts, ${ }^{8}$ though this is not supported by the long history of chest symptoms before the appearance of the chest wall mass and the absence of radiological evidence of sternal erosion.

Since $\boldsymbol{A}$ actinomycetemcomitans is believed to be a mouth commensal, it has been proposed that the mouth or respiratory tract may serve as a portal of entry, either by direct invasion ${ }^{4}$ or via paratracheal lymph nodes. ${ }^{9}$ In one study a large proportion of mediastinal abscesses were said to have occurred by direct downward extension along the fascial planes of a retropharyngeal or parapharyngeal abscess. ${ }^{10}$ Most of these were situated in the superior mediastinum around the oesophagus and spread of infection to the left side was limited by the aortic arch. The anterior mediastinum was affected very rarely, and when it occurred this was usually due to spread from the posterior mediastinum. In our case, however, the absence of obvious oral, cervical, or endobronchial lesions and the location of the abscess make this route of entry unlikely. Despite the failure to grow the organism from bronchial washings and swabs of the teeth and throat, the isolation of $A$ actinomycetemcomitans in pure culture from pus suggests that this was the sole causative organism in this case.

The rarity of isolation of this organism may be related in part to its capnophilic and slow-growing properties. ${ }^{23}$ This report highlights the need for awareness of such growth characteristics in the investigation of unusual infections, 

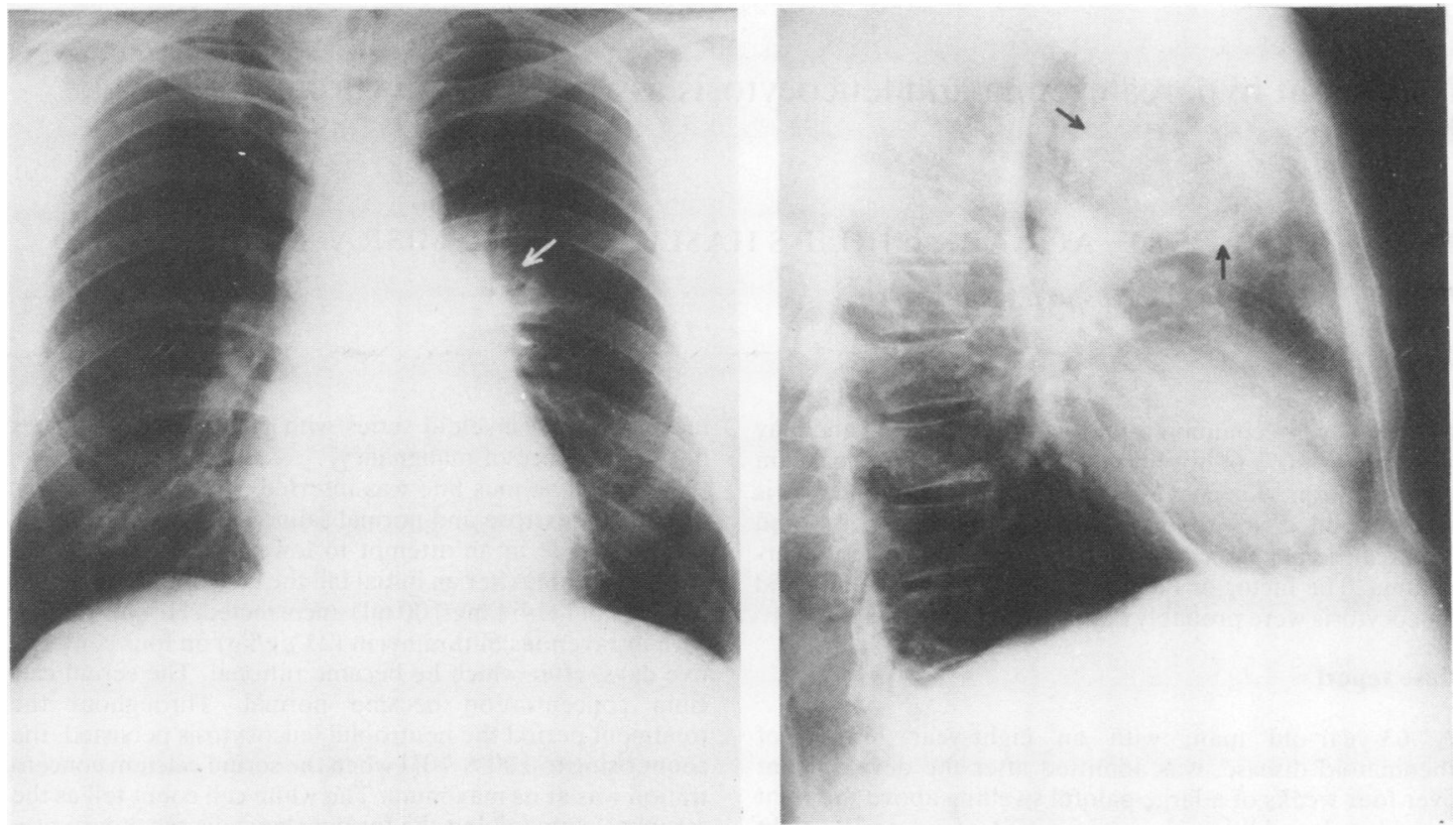

Posteroanterior and lateral chest radiographs showing a large anterosuperior mediastinal mass (arrows).

and documents a successful outcome from severe infection in a site generally associated with a high mortality rate.

We wish to thank Margaret Peel and Mr KN Sim, microbiological diagnostic unit, University of Melbourne, Australia, for their assistance in identification of the organism, and Drs ER Pavillard, department of microbiology, and AR Rubinfeld, department of thoracic medicine, for their advice and criticism.

\section{References}

${ }^{1}$ Heinrich S, Pulverer G. Zur Aetiologie und Mikrobiologie der Actinomykose. III-Die pathogene Bedeutung des Actinobacillus actinomycetemcomitans unter den "Begleitbakterien" des Actinomyces israeli. Zentralbl Bakteriol 1959;176:91-101.

${ }^{2}$ Klinger R. Untersuchungen über menschliche Actinomykose. Zentralbl Bakteriol 1912;62:191-200.
${ }^{3}$ Vandepitte J, De Geest H, Jousten P. Subacute bacterial endocarditis due to Actinobacillus actinomycetemcomitans. Report of a case and a review of the literature. J Clin Pathol 1977;30:842-6.

${ }^{4}$ Page MI, King ED. Infection due to Actinobacillus actinomycetemcomitans and Haemophilus aphrophilus. N Engl $J$ Med 1966;275:181-8.

${ }^{s}$ Ellner JJ, Rosenthal MS, Lerner PI, McHenry MC. Infective endocarditis caused by slow growing fastidious Gram-negative bacteria. Medicine (Baltimore) 1979;58:145-56.

- Geraci JE, Wilson WR, Wasthington JA. Infective endocarditis caused by Actinobacillus actinomycetemcomitans. Mayo Clin Proc 1980;55:415-9.

'Cowan ST, Steel KJ. Cowan and Steel's manual for the identification of medical bacteria. 2nd ed. London: Cambridge University Press, 1974.

${ }^{8}$ Keefer CS. Acute and chronic mediastinitis-a study of sixty cases. Arch Intern Med 1938;62:109-36.

${ }^{9}$ Lerche W. Infected mediastinal lymph nodes as a source of mediastinitis. Arch Surg 1927;14:285-305.

${ }^{10}$ Neuhof H, Rabin CB. Acute mediastinitis. Roentgenological, pathological and clinical features and principles of operative treatment. Am J Roentgenol 1940;44:684-703. 